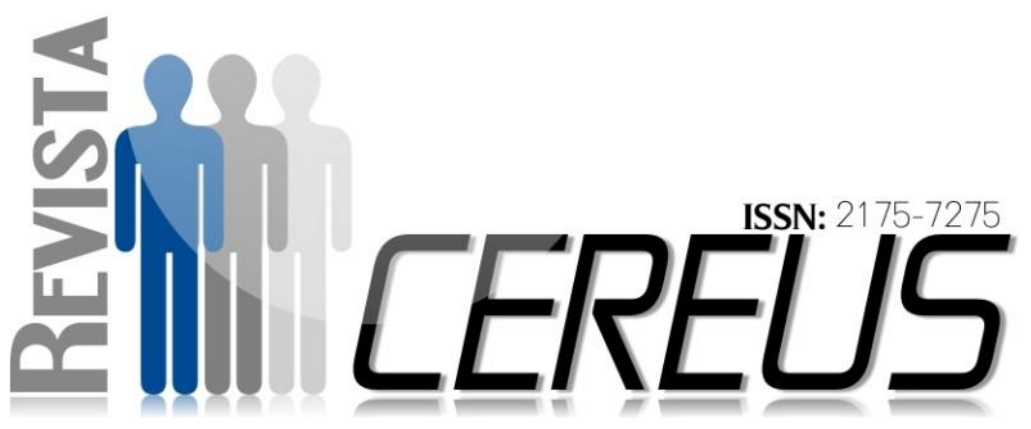

DOI:10.18605/2175-7275/cereus.v9n1p.132-145

\title{
ACEPÇÃO DO ESPORTE ADAPTADO POR COMPETIDORES DE ATLETISMO NAS OLIMPÍADAS ESPECIAIS DO TOCANTINS
}

\author{
RIELLA JUNIOR, José Luiz de Carvalho ${ }^{1}$ \\ BARTHOLOMEU NETO, João \\ SOUZA, Marcos Junio Graciano de ${ }^{2}$ \\ FARENCENA, Eliana Zellmer $\mathrm{P}^{2}$
}

\section{RESUMO}

O Brasil tem obtido bons resultados nas últimas edições dos jogos paraolímpicos. Apesar disso, paratletas amadores enfrentam dificuldades em treinos e competições regionais e, dessa forma, desfrutam parcialmente dos benefícios do esporte adaptado. O presente estudo buscou identificar a acepção do esporte adaptado para os alunos com deficiência intelectual e física da APAE (Associação de Pais e Amigos dos Excepcionais) de Gurupi-TO. Tratou-se de um estudo exploratório e descritivo, de natureza qualitativa. A amostra da pesquisa contou com 6 (seis) alunos jovens e adultos de ambos os sexos com deficiência intelectual e física, da APAE de Gurupi-TO, que competiram nas Olimpíadas Especiais das APAEs do Tocantins nas modalidades do atletismo. Os voluntários responderam a uma entrevista contendo quatro

\footnotetext{
${ }^{1}$ Graduado em Educação Física pela UnirG, Gurupi -TO E-mail: junior_riella@hotmail.com

${ }^{2}$ Professores do curso de Educação Física - UnirG, Gurupi-TO
} 
questões geradoras: Quais são as suas dificuldades para participar do atletismo nas Olimpíadas especiais das APAES? O que você sente quando está competindo com os outros atletas? O que você espera em relação às Olimpíadas daqui para frente? O que significa o esporte na sua vida? As respostas foram gravadas e transcritas utilizando-se a Análise de Conteúdo: "Técnica de Elaboração e Análise de Unidades de Significado". Os resultados revelam que, ao participarem das olimpíadas da APAE, os voluntários sentem dificuldades físicas, estruturais e emocionais, esperam melhorias e desejam vencer para agradar a família, sentem mais felizes e fazem novas amizades. Conclui-se que o atletismo adaptado constitui uma possibilidade de superação devido às dificuldades e pela vontade de vencer; responsabilidade pela busca de reconhecimento próprio e da família; e inclusão social pelas amizades que as competições esportivas proporcionam.

Palavras-chave: Deficiência Intelectual e Física. Esporte Adaptado. Atletismo. Olimpíadas Especiais.

\section{ACCEPTANCE OF ADAPTED SPORT BY ATHLETES COMPETITORS IN THE SPECIAL OLYMPICS GAMES OF TOCANTINS}

\section{ABSTRACT}

Brazil has achieved good results in the last editions of the Paralympic Games. Nonetheless, amateur paratlete face difficulties in training and regional competitions and thus partially enjoy the benefits of adapted sport. The present study sought to identify the meaning of the sport adapted to the students with intellectual and physical disabilities of APAE (Association of Parents and Friends) of Gurupi-TO. It was an exploratory and descriptive study of a qualitative nature. The 
research sample included 6 (six) young and adult students of both gender with intellectual and physical disabilities, from APAE de Gurupi-TO, who competed in the Special Olympics of the APAEs of Tocantins in the modalities of athletics. The volunteers responded to an interview containing four generating questions: What are your difficulties in participating in athletics at the APAES Special Olympics? What do you feel when you're competing with the other athletes? What do you expect from the Olympics going forward? What does sport mean in your life? The responses were recorded and transcribed using the Content Analysis: "Technique of Elaboration and Analysis of Units of Significance". The results show that by participating in the APAE Olympic games, volunteers experience physical, structural and emotional difficulties, expect improvements and wish to win to please their families, feel happier and make new friendships. It is concluded that adapted athletics constitutes a possibility of overcoming due to the difficulties and the will to overcome; responsibility for seeking self-recognition and family; and social inclusion by the friendships that the sport competitions provide.

Key Words: Intellectual and Physical Disability. Adapted Sport. Athletics. Special Olympics. 


\section{INTRODUÇÃO}

Dados do Instituto Brasileiro de Geografia e Estatística (IBGE) apontam que $24 \%$ da população brasileira declarou possuir algum tipo de deficiência. São 46 milhões de pessoas vivendo com alguma deficiência, que pode ser visual, auditiva, física, mental, múltiplas, entre outras (XAVIER, 2015).

A Deficiência Intelectual é uma das mais frequentes em crianças e adolescentes, com estimativa de até $5 \%$ da população mundial (GIMENEZ, 2013). Seu diagnóstico envolve fatores biomédicos, etiológicos, comportamentais, sociais e educacionais, que resultam em uma complexidade para trabalhar com a educação e esporte com esses jovens (HONORA, FRIZANCO, 2008). A deficiência física está relacionada ao aparelho locomotor e algum tipo de comprometimento para a realização dos padrões motores esperados ou considerado normal para o ser humano (BRASIL, 2006). No esporte adaptado, a classificação da deficiência física é de acordo com o aparecimento, a etiologia, a localização e a origem (DIEHL, 2008).

A prática esportiva e a competição sugerem a busca por desempenho, com possibilidade de superação dos limites e o prazer dessa conquista (FEITEN E PERGHER 2010), além dos efeitos sociais e emocionais (BRAZUNA E CASTRO 2001). O esporte adaptado, não pode ser identificado apenas com a potencialização atlética, mas, como uma prática cultural que promove socialização, educação e experimentação de distintas possibilidades de movimento, evitando a exclusão (SOARES, 2009). Nesse sentido, busca-se que nenhum educando fique marginalizado das práticas esportivas e espera-se que essas vivências contribuiriam na sua formação e reflitam para a cidadania (Moura et al, 2012). O esporte adaptado possui o valor social da igualdade, apesar das diferenças e a maioria dos deficientes físicos se beneficiam da prática da Educação Física e modalidades esportivas adaptadas, as quais estão em constante expansão e desenvolvimento (WINNICK, 2004). Assim, O esporte adaptado proporciona aos participantes inúmeros benefícios, aptidão física, independência e autoconfiança, autocontrole e da autoestima 
(GORGATTI, GORGATTI, 2005).

Dentre os vários esportes adaptados, o atletismo vem se destacando quanto ao número de adeptos e um dos grandes fatores de difusão da modalidade é o fácil acesso e a naturalidade dos movimentos (COSTA, SILVA, 2013). O atletismo é um dos esportes que o Comitê Paraolímpico Brasileiro indica que seja praticado por atletas com deficiência física ou visual. Existem provas de corrida, saltos, lançamentos e arremessos que são divididos em categorias de acordo com o grau de deficiência constatado pela classificação funcional (GORGATTI, 2005).

As Olimpíadas Especiais das APAEs são promovidas pela Federação das APAEs do Estado do Tocantins - FEAPAES - TO, com apoio das APAEs, órgãos do Governo Estadual, Prefeituras Municipais, entidades civis, empresas, voluntários e outros parceiros. Podem disputar os Jogos Especiais das APAEs apenas os alunos vinculados às APAEs do Tocantins, em instituições especializadas e em escolas regulares de ensino, desde que se comprove através de exames psicológicos a(s) deficiência(s)

existente(s)

(REGULAMENTO GERAL DAS OLIMPÍADAS ESPECIAIS DAS APAES- TO, 2014).

O profissional de Educação Física das APAEs não pode restringir à preparação de atletas para a Olimpíada, mas ter como principal objetivo a ampliação das "potencialidades das pessoas com deficiência, por meio de atividades lúdicas coletivas, que visam à adoção de atitudes cooperativas e solidárias, sem discriminar os colegas pelo desempenho ou por razões sociais, físicas, sexuais ou culturais" (APAE BRASIL, 2010).

Apesar do Brasil ter obtido bons resultados nas últimas edições dos jogos paraolímpicos, paratletas amadores enfrentam uma série de dificuldades em treinos e competições regionais. Nesse sentido, os benefícios do esporte adaptado são parcialmente atingidos. Dessa forma, o presente estudo tem como objetivo identificar a acepção do esporte para os alunos com deficiência intelectual e física da APAE de Gurupi que competem nas olimpíadas especiais do Tocantins. 


\section{METODOLOGIA}

A pesquisa, de natureza qualitativa, foi realizada na $A P A E$ de Gurupi-TO, por meio de entrevista aos alunos praticantes da modalidade de Atletismo adaptado: salto em distância, Arremesso de dardo, Corrida de 100 metros, Arremesso de peso e Revezamento.

Após ter a autorização do local para realizar a pesquisa e 0 consentimento dos voluntários, foram agendadas e realizadas entrevistas de acordo a disponibilidade de cada sujeito da pesquisa.

Os sujeitos da pesquisa foram 6 (seis) alunos regulamente matriculados na APAE de Gurupi-TO de ambos os sexos, faixa etária entre 15 a 25 anos, com deficiência física e intelectual com grau "leve". Todos praticantes da modalidade atletismo que participaram das Olimpíadas Especiais do Tocantins nas últimas duas edições e aceitaram participar da pesquisa com os pais ou responsáveis.

Em visita anterior à instituição, foi informado que seis alunos com deficiência intelectual e física participavam das modalidades de Atletismo nas Olimpíadas da APAE TO. Portanto, todos os voluntários que se encaixavam nos critérios de inclusão foram entrevistados e ao final não houve perda amostral.

As entrevistas foram realizadas em dias e horários pré-agendados de comum acordo com os voluntários e responsáveis, preferencialmente que acontecesse com calma e não atrapalhasse a rotina dos participantes. Foi apresentado 0 termo de consentimento livre e esclarecido aos responsáveis dos alunos por eles serem pessoas vulneráveis contendo o objetivo da pesquisa, bem como os benefícios para os sujeitos, esclarecendo aos responsáveis a importância da participação dos voluntários para 0 incentivo e esclarecimento para a comunidade científica e comunidade em geral das questões que envolvem o esporte e a participação dos mesmos nas Olimpíadas especiais.

Antes de iniciar a entrevista, foi explicado a cada sujeito que este poderia usar o tempo que julgar necessário para refletir sobre a sua resposta. Para a entrevista foi utilizado um celular da marca Samsung® para a gravação e as entrevistas foram posteriormente transcritas. 
Como instrumento de coleta de dados, utilizamos a entrevista estruturada tendo o objetivo de levantar informações dos pesquisados de forma direta entre os sujeitos e o pesquisador. Para a coleta de dados, adotamos uma entrevista com quatro questões geradoras a todos os voluntários:

Questão 01: Quais são as suas dificuldades para participar do atletismo nas Olimpíadas especiais das APAES?

Questão 02: O que você sente quando está competindo com os outros atletas?

Questão 03: O que você espera em relação às Olimpíadas daqui para frente?

\section{RESULTADOS}

No quadro 01 (um) são apresentadas as unidades de significado relacionadas à questão 01 : Quais são as suas dificuldades para participar do atletismo nas Olimpíadas especiais das APAES? Observa-se que $66,6 \%$ dos entrevistados responderam "Dificuldades físicas e estruturais". As unidades de significado "Dificuldades Emocionais" e "Dificuldades Técnicas" foram respondidas por $16,6 \%$ dos sujeitos.
Questão 04: $O$ que significa 0 esporte na sua vida?

Para análise dos resultados, foi utilizado a técnica de análise de conteúdo elaborada por Moreira, Simões e Porto (2005), designada como Análise de Conteúdo: Técnica de Elaboração e Análise das Unidades de Significados.

Os resultados, analisados de forma qualitativa, foram agrupados em unidades de significado e apresentados em quadros apontando a relação com o discurso de cada sujeito e sua frequência relativa.

Em relação à questão 02: $\mathrm{O}$ que você sente quando está competindo com os outros atletas? A "Vontade de Ganhar" foi a unidade de significado mais frequente, encontrada nas respostas de $66,6 \%$ dos sujeitos. A segunda e a terceira unidades de significado foram encontradas nas respostas de $16,6 \%$ dos sujeitos sendo "Medo" e "Garra/Orgulho". 
Quadro 01 - Unidade de significados referente às respostas da questão 01 - Quais são as suas dificuldades para participar do atletismo nas Olimpíadas especiais das APAES?

\begin{tabular}{|c|c|c|c|c|c|c|c|c|}
\hline & $\begin{array}{l}\text { Unidades de } \\
\text { Significados }\end{array}$ & $\begin{array}{l}\bar{\delta} \\
\stackrel{0}{0} \\
\stackrel{0}{0} \\
\stackrel{5}{\sigma} \\
\omega\end{array}$ & $\begin{array}{l}\text { ㅇ } \\
\stackrel{0}{0} \\
\stackrel{0}{0} \\
\stackrel{5}{5}\end{array}$ & 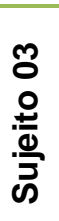 & 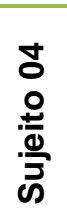 & $\begin{array}{l}\text { L } \\
\text { ᄋ } \\
\stackrel{2}{0} \\
\stackrel{5}{5}\end{array}$ & 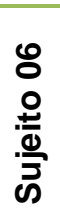 & $\%$ \\
\hline 1 & Dificuldades físicas e estruturais & $\mathrm{X}$ & $\mathrm{X}$ & $\mathrm{X}$ & & & $\mathrm{X}$ & $66,6 \%$ \\
\hline 2 & Dificuldades emocionais & & & & $\mathrm{X}$ & & & $16,6 \%$ \\
\hline 3 & Dificuldades técnicas & & & & & $\mathrm{x}$ & & $16,6 \%$ \\
\hline
\end{tabular}

Quadro 02 - Unidades de significados referente as respostas da questão 02 - O que você sente quando está competindo com os outros atletas?

\begin{tabular}{|c|c|c|c|c|c|c|c|c|}
\hline & $\begin{array}{l}\text { Unidades de } \\
\text { Significados }\end{array}$ & $\begin{array}{l}5 \\
0 \\
\stackrel{0}{ \pm} \\
\stackrel{0}{3}\end{array}$ & 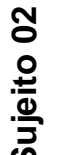 & $\begin{array}{l}m \\
0 \\
0 \\
\stackrel{0}{0} \\
\frac{0}{3}\end{array}$ & $\begin{array}{l}\text { O } \\
0 \\
\stackrel{0}{0} \\
\frac{0}{3}\end{array}$ & $\begin{array}{l}\stackrel{2}{0} \\
\circ \\
\stackrel{\circ}{0} \\
\frac{0}{3}\end{array}$ & 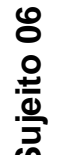 & $\%$ \\
\hline 1 & Vontade de ganhar & & $X$ & $\mathrm{X}$ & & $x$ & $X$ & $66,6 \%$ \\
\hline 2 & Medo & $\mathrm{X}$ & & & & & & $16,6 \%$ \\
\hline 3 & Garra/orgulho & & & & $\mathrm{x}$ & & & $16,6 \%$ \\
\hline
\end{tabular}

Quadro 03 - Unidade de significados referente as respostas da questão 03 - O que você espera em relação às Olimpíadas daqui para frente?

\begin{tabular}{|c|c|c|c|c|c|c|c|c|}
\hline \multicolumn{2}{|r|}{$\begin{array}{l}\text { Unidades de } \\
\text { Significados }\end{array}$} & $\begin{array}{l}\overline{0} \\
0 \\
\stackrel{0}{0} \\
\stackrel{0}{3} \\
0\end{array}$ & 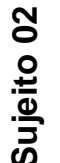 & 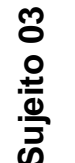 & 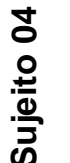 & 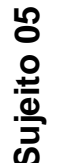 & 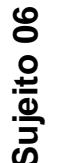 & $\%$ \\
\hline 1 & $\begin{array}{l}\text { Vencer para ficar feliz e agradar minha } \\
\text { família }\end{array}$ & & $X$ & $X$ & & $X$ & $X$ & $66,6 \%$ \\
\hline 2 & $\begin{array}{l}\text { Fazer amizades e conhecer novos } \\
\text { lugares }\end{array}$ & $X$ & $X$ & $X$ & & & & $50 \%$ \\
\hline 3 & $\begin{array}{l}\text { Jogos mais organizados e } \\
\text { estruturados }\end{array}$ & $x$ & & & $X$ & $\mathrm{X}$ & & $50 \%$ \\
\hline
\end{tabular}

As respostas em relação à frente? Destaca-se a unidade de questão 03: O que você espera em significado "Vencer para ficar feliz e relação às Olimpíadas daqui para agradar minha família" em $66,6 \%$ das Rev. Cereus, v. 9, n. 1, p.132-145, jan-abr./2017, UnirG, Gurupi, TO, Brasil. 
respostas. A segunda e terceira unidades de significado é "Fazer amizades e conhecer novos lugares" e "jogos mais organizados e estruturados" corresponderam a 50\% dos sujeitos pesquisados.

Ao analisar as respostas referentes à questão $04:$ O que significa o esporte na sua vida? A unidade de significado "O esporte é tudo" se enquadrou em $100 \%$ das respostas dos sujeitos. A segunda unidade de significado observada foi "Viver melhor" correspondendo a $16,6 \%$.

Quadro 04 - Unidade de significados referente as respostas da questão 04 - O que significa o esporte na sua vida?

\begin{tabular}{|c|c|c|c|c|c|c|c|c|}
\hline & $\begin{array}{l}\text { Unidades de } \\
\text { Significados }\end{array}$ & 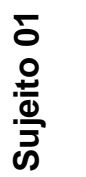 & 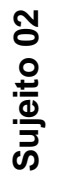 & 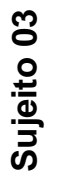 & 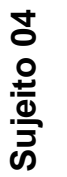 & 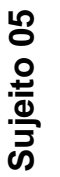 & 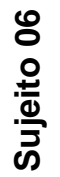 & $\%$ \\
\hline 1 & O esporte é tudo & $X$ & $X$ & $\mathrm{X}$ & $X$ & $\mathrm{X}$ & $\mathrm{X}$ & $100 \%$ \\
\hline 2 & Viver melhor & & & & $\mathrm{X}$ & & & $16,6 \%$ \\
\hline
\end{tabular}

\section{DISCUSSÃO}

Em relação às dificuldades para participar do atletismo nas Olimpíadas especiais das APAES, foi observado que as Dificuldades físicas e estruturais representam $66,6 \%$ das respostas. Dentre elas, a que mais chamou atenção foi do sujeito número 2 "[...] $\mathrm{Na}$ corrida é difícil e a quadra [...]".

A Dificuldade Emocional foi respondida por $16,6 \%$ dos sujeitos. Nesta unidade destacamos a fala do sujeito 4 que diz "[...] Minhas dificuldades são nervosismo na hora e muita ansiedade... sou muito pessimista [...]". Diante do relato deste sujeito podemos observar que alguns aspectos emocionais interferem na prática do atletismo nas olimpíadas das APAEs.

A Dificuldade Técnica compreendeu $16,6 \%$ das respostas dos voluntários. Segundo o sujeito 5: "[...] minha dificuldade é quando não consigo treinar na hora que eu chego para arremessar um peso para arremessar um dardo e aí fica difícil a gente se sente o corpo todo dolorido todo machucado [...]". 
A participação dos deficientes em práticas esportivas contribui significativamente para melhorar todas as dimensões da qualidade de vida. Os esportes ainda alcançam objetivos sociais e emocionais, além da ocupação do tempo ocioso (BRAZUNA, CASTRO 2001). As dificuldades encontradas no meio do desporto adaptado são diversas, acordo com cada deficiência e o grau de comprometimento. Nesse caso, é importante que os profissionais atuantes tenham amplo conhecimento sobre o tipo e o grau da deficiência, fazer as adaptações corretas e utilizar os materiais mais adequados (DIEHL, 2008).

Em relação ao que 0 atleta sente quando está competindo com os outros atletas, foi observado que a Vontade de Ganhar, foi encontrada em $66,6 \%$ das respostas. O sujeito 3, "[...] Eu quero muito ganhar e penso que eu quero ganhar muito ouro[...]", já o sujeito 5 relatou que sente quando está competindo "[...] Eu sinto um cara que chegou ali não foi por querer, foi por batalha, foi por vencer na vida. Foi para o treino foi treinando, foi um cara que assim dia- a- dia ele não parava de treinar, aí eu me sinto assim até feliz por que eu tenho várias medalhas e quando eu tô competindo eu não compito para perder eu compito para ganhar, eu quero ser o primeiro lugar, se não for o primeiro lugar não serve para $\operatorname{mim}[. .]$.$" .$

O Medo foi o sentimento relatado por $16,6 \%$ dos sujeitos como dificuldade na prática da atividade, a qual segue: "[...]Oh, eu me sinto com medo de eu perder e não chegar lá, tem hora que as pernas não alcançam no atletismo, perco a força, mas eu vou querer me esforçar muito "pra mim" chegar não cansar [...]".

A Garra/Orgulho foram relatadas por $16,6 \%$ dos sujeitos, sendo este o participante relatou "[...] Me sinto um Guerreiro; Que também temos o direito de mostrar que somos atletas especiais [...]".

Uma mudança na mentalidade é necessária no cenário nacional. As pessoas devem parar de pensar nesses atletas como "coitadinhos" e "esforçadinhos" e enxergá-los como atletas que realmente são. O objetivo maior do esporte adaptado é a competição e esse fato não diminui os demais benefícios de sua prática, principalmente psicossociais (GREGUOL, GORGATTI, 2013).

A competição associa-se à superação individual (motivação 
intrínseca) em conjunto com a motivação extrínseca, provocada pelo adversário ou requerimento da prova atlética (BRAZUNA, CASTRO, 2001).

Para o portador de deficiência, a prática esportiva possibilita 0 conhecimento e a vivência do significado da superação de limites e a confirmação de que ele pode conquistar e viver esse prazer (FEITEN, PERGHER, 2010).

Quanto ao que os entrevistados esperavam em relação às Olimpíadas daqui para frente, foi relatado que vencer para ficar feliz e agradar minha família foi a resposta mais frequente $(66,6 \%)$. O sujeito 5 relata que "[...] treina com prazer treina com o coração que a gente vai ali é pra vencer". O sujeito 6 corrobora, dizendo "[...] e meu pai gosta muito eu ganhar e eu já tenho um bocado de medalhas lá em casa, eu fico com muita alegria".

Fazer amizades e conhecer novos lugares, foi respondido por $50 \%$ dos sujeitos pesquisados, a fala que mais nos chamou atenção foi "[...] e vamos e conhecer muitos colegas lá nas olimpíadas e fazer muitas amizades[...]".

A metade (50\%) dos entrevistados afirmam esperar que os jogos sejam melhor organizados e estruturados. O sujeito $4 \mathrm{diz}$ que "[...] Daqui pra frente eu espero melhorias né por que eu já participo a sete anos das olimpíadas da APAE de Gurupi e a gente de uns anos para cá vem tendo muitas dificuldades, espero que eles pensem um pouco na melhoria, organizar mais[...]". O sujeito 5 diz ainda que "[...] Sim, eu espero quando eu chegar lá nas olimpíadas esteja tudo arrumado[...]".

Desde 1973, as Olimpíadas Especiais das APAES buscam proporcionar a participação dos estudantes desta instituição de um evento nacional, oportunizando momentos de interação e integração, uma vez que frequentemente são impossibilitados pelas barreiras físicas e sociais. O atletismo adaptado é uma das atividades motoras mais praticadas nas instituições de educação especial e busca-se a convivência em grupo através da integração com os colegas (POTRICH, 1996). Dessa forma, o atletismo constitui-se em um caminho eficaz para o desenvolvimento motor, incentivando seus interesses através de suas conquistas individuais e trabalhando na construção de sua interação em grupo (MOURA et al., 2006). 
Percebemos que a grande satisfação de poder se interagir, e buscar a igualdade mostrando para a sociedade que eles também são capazes de vencer seus próprios desafios, e serem motivos de inspiração para os que os veem competindo, e para seus familiares, que na maioria das vezes dão apoio e suporte (MOURA et al., 2012).

Foi possível observar que, as olimpíadas ou jogos apaeanos ainda pode melhorar enquanto estrutura e organização. De acordo com o artigo 1 do regulamento dos jogos especiais assegura-se da segurança a todos os alunos com deficiência em todos os níveis, promovendo a integração entre os alunos e a comunidade, favorecendo o desenvolvimento pleno de suas capacidades e fazendo do esporte um verdadeiro instrumento de inclusão (APAE TOCANTINS, 2015).

Empecilhos para disseminação do esporte adaptado incluem transporte e instalações adaptadas. Embora exista diretrizes a serem seguidas, na prática existem muitas irregularidades estruturais que dificultam a rotina de treinamento (GREGUOL, GORGATTI, 2013).

Sobre o significado do esporte para a vida dos participantes, todos afirmaram "O esporte é tudo". A resposta que mais chamou a atenção foi a do sujeito número 5 "[...]Se não fosse o esporte eu não era nada na vida, o esporte para mim significa muito, eu faço arremesso de dardo arremesso de peso, arremesso de disco, o esporte na vida para a gente é muito bom[...]".

Um participante respondeu que esporte na sua vida significa viver melhor. Em sua fala: "[...] O esporte na minha vida é tudo, foi através do esporte que eu me adaptei que eu consegui viver melhor [...]".

Quando o sujeito diz que o esporte é tudo ou que ajuda a viver melhor, nos faz refletir sobre a profundidade dessas respostas. Nesse sentido, autoridades, professores e demais profissionais que atuam diretamente ou indiretamente com portadores de deficiências devem repensar o valor do esporte.

Para efetivar uma verdadeira inclusão pelo esporte é necessário assumir novos olhares sobre todos os corpos, não enfatizando as limitações, mas principalmente, as possibilidades que cada um expressa (SOARES, 2009). A prática esportiva adaptada pode se constituir em um extraordinário recurso para aprender a ser e a 
conviver. A participação de uma pessoa com deficiência no esporte representa uma forma saudável de lazer ativo, que permite envolvimento e interação.

O presente estudo permite reflexões sobre a prática e participação de competições de atletismo adaptado nas olimpíadas especiais da APAE.

\section{CONSIDERAÇÕES FINAIS}

Foi possível observar, por meio dos discursos dos voluntários, que o desempenho esportivo e o resultado atlético são importantes, pois há vontade de vencer. Apesar disso, observa-se a valorização de uma diversidade de experiências significativas que o esporte proporciona em relação a sentimentos, dificuldades e desafios. As competições vêm acompanhadas de sentimentos como
Contudo, algumas limitações devem ser ressaltadas para a extrapolação de nossos resultados. Destacamos que entrevistamos apenas seis voluntários, que são da mesma instituição, deficientes físicos e intelectual, que competiram em provas de atletismo. medo e orgulho, além da responsabilidade para provar a si e aos familiares que se prepararam de forma adequada. Resultados positivos permitem aumento na autoestima e as competições são oportunidades para conhecer lugares $\mathrm{e}$ interagir com pessoas, acompanhadas de percepção de reconhecimento, inclusão e superação.

\section{REFERÊNCIAS}

BRASIL. Ministério da Educação, Secretaria de Educação Especial. A inclusão escolar de alunos com necessidades educacionais especiais- DEFICIÊNCIA FíSICA. Brasília - DF: 2006.

BRAZUNA, M.; CASTRO, E. A trajetória do atleta portador de deficiência física no esporte adaptado de rendimento. Uma revisão da literatura. Motriz, 2001.

DIEHL, R. M. Jogando com as diferenças: jogos para crianças e jovens com deficiência: em situação de inclusão e em grupos específicos / Rosilene Morais Diehl. - 2. Ed. - São Paulo: Phorte, 2008 il.

GIL, A. C. Como elaborar projetos de pesquisa. 5. Ed São Paulo: atlas, 2008. 
GIMENEZ, R. Atividade Física e Deficiência Mental in GORGATTI ; M,G. COSTA; R.F. Atividade Física Adaptada qualidade de vida para pessoas com necessidades especiais. 3 ed. Barueri-SP: Editora Manole 2013 Cap. 3, p.78 - 125.

GORGATTI, M. G; COSTA, R. F. Atividade Física Adaptada. Barueri: Manole, 2005.

GORGATTI, M. G. ; COSTA, R. F. ; MATTOS, E.. Atividade física nos distúrbios neurológicos e musculares. In: GORGATTI, M. G.; COSTA, R. F.. (Org.). Atividade física adaptada - qualidade de vida para pessoas com necessidades especiais. 3ed.Barueri. : Manole. 2013.v. 1, p. 221-253.

HONORA M., FRIZANCO M. L., Esclarecendo as deficiências: Aspectos teóricos e práticos para contribuir com uma sociedade inclusiva. Ciranda Cultural, 2008.

MOREIRA, W.W. SIMOES, R., PORTO E. análise de conteúdos: técnica de elaboração e analise de unidades de significados. Revista Brasileira de Ciência e Movimento, v.13, n.4, 2005. P.107-114

Moura, W.L. et al. Importância da prática esportiva como meio de inclusão social para pessoas com deficiência mental na cidade de Montes Claros - MG Motricidade, vol. 8, núm. Supl. 2, 2012, pp. 613-623.

MOURA, W.L.; BENDA, R. N.; NOVAES, J. S.; TUBINO, M. J. G. O Atletismo no desenvolvimento de crianças portadoras de necessidades especiais. Motricidade V.2 N.1, p. 53-61, 2006.

POTRICH, A. C. Deficiência mental. In: Neto, F. C; Gonzales, J. J. Desporto adaptado a portadores de deficiência: atletismo. Porto Alegre: INDESP/UFRGS, 1996.

REGULAMENTO GERAL E TÉCNICO DA OLIMPÍADA DAS APAES. VIII Olimpíadas Especiais das APAEs. Tocantins: 2014.

TRIVIÑOS, A.N.S. Introdução à Pesquisa em Ciências Sociais: a pesquisa qualitativa em educação. São Paulo: Atlas, 1987.

XAVIER, Marcia de Azevedo Alves. Assistência Social e pessoa com deficiência: um estudo sobre os programas e serviços ofertados à pessoa com deficiência nos Centros de Referência de Assistência Social/CRAS na zona leste e norte da cidade de Manaus. - Manaus, 2015. 84 f. (dissertação de mestrado).

WINNICK, J. P. Educação Física e Esportes Adaptados. Barueri: Manole, 2004. 